\title{
Modifying Atlantic salmon behaviour with light or feed stimuli may improve parasite control techniques
}

\author{
Samantha Bui ${ }^{1}$, Frode Oppedal ${ }^{2}$, Øyvind J. Korsøen ${ }^{2}$, Tim Dempster ${ }^{1,3, *}$ \\ ${ }^{1}$ Sustainable Aquaculture Laboratory - Temperate and Tropical (SALTT), Department of Zoology, University of Melbourne, \\ Victoria 3010, Australia \\ ${ }^{2}$ Institute of Marine Research, 5984 Matredal, Norway \\ ${ }^{3}$ Centre for Research-based Innovation in Aquaculture Technology (CREATE), SINTEF Fisheries and Aquaculture, \\ 7465 Trondheim, Norway
}

\begin{abstract}
The aquaculture of Atlantic salmon Salmo salar faces severe health, environmental and economic concerns caused by the parasitic sea lice Lepeophtheirus salmonis and Caligus spp. An experimental delousing method exists whereby the surface jumping behaviours of salmon are combined with a floating, oil-infused chemical therapeutant, resulting in the fish dousing themselves passively. We tested whether a light stimulus or feed event, or a combination of both, during submergence (denial of surface access for the fish) increased the surface-oriented behaviours of salmon. Groups of 10 salmon were submerged in a sea-cage for $19 \mathrm{~h}$ and exposed to a light stimulus, feed event, or both. Control treatments involved submergence only. For a $2 \mathrm{~h}$ period after surface access was reinstated, light and feed treatments induced a higher proportion of individuals to exhibit surface behaviours. On average, 84 and $82 \%$ of salmon in the light and feed treatments jumped, respectively, which was 1.6 times higher than fish in the control group $(50 \%)$. Salmon exposed to light or feed jumped an average of 1.7 and 1.5 times after exposure to light or feed treatments, respectively, compared to 0.92 jumps fish $^{-1}$ for the control. The combined light and feed treatment did not produce a synergistic effect. The average time until first jump was 31 to $50 \mathrm{~min}$, with no difference in times among treatments. The elevated surface-oriented behaviours effectively crowded the majority of the fish in the surface waters within a short period of time. This increased surface activity may be used for a range of salmon farming applications, including improving the efficacy of sea-lice treatment techniques.
\end{abstract}

KEY WORDS: Aquaculture - Salmo salar - Sea lice - Swim bladder · Buoyancy - Surface behaviours · Submergence · Caligus spp. - Lepeophtheirus spp. Environmental impact

\section{INTRODUCTION}

Maintaining healthy populations is one of the greatest challenges to modern industrial fish farming (Bergh 2007), where the high densities of fish promote the proliferation of infective agents. Successful methods to tackle fish health issues must be effective, cause limited stress to the fish, avoid the rapid development of resistance to the treatment agent, and not cause significant environmental impacts. Developing techniques that meet all of these charac- teristics is difficult. Recent advances suggest that a deeper understanding of the behavioural repertoire of fish under farming conditions may provide opportunities to improve existing treatment methods and develop new ones (Dempster et al. 2011, Oppedal et al. 2011a).

Infective sea lice (Lepeophtheirus salmonis and Caligus spp.) plague modern industrial salmon aquaculture in the sea; they limit production and economic efficiency, negatively affect animal welfare, and their impacts extend beyond production facilities 
to the wider environment (review: Costello 2006). Salmon farms amplify infestation pressures on wild populations of salmon in coastal areas, particularly those in close proximity to the intense clusters of farmed fish (Krkoŝek et al. 2005, 2013). The control of sea lice is thus critical for conservation of wild salmon (Costello 2009). Keeping lice prevalence in sea-cages low and standardising the methods of applying delousing treatments are significant challenges (Heuch \& Mo 2001, Westcott et al. 2004).

Multiple methods are currently used to control sea lice, with a common approach being topical delousing treatments using chemical baths. The effectiveness of bathing is difficult to assess (Jimenez et al. 2012) and is declining as the parasites build resistance to the chemical (Jones et al. 1992, Denholm et al. 2002). Furthermore, there is concern regarding the welfare implications of chemical baths, as farmers have reported reduced growth and appetite, greater prevalence of other diseases, and higher rates of mortality in fish following the treatment (F. Oppedal pers. obs.). After the treatment, toxic chemicals are released into the environment, which pollutes surrounding habitats and may affect non-target organisms (Burridge et al. 2010).

An alternative approach to controlling sea lice involves utilising the natural anatomy and behaviour of salmon to create an opportunity for a passive delousing treatment. Farmed salmon exhibit 'porpoising' rolling and jumping behaviours at the surface (Furevik et al. 1993) at infrequent intervals (i.e. less than once per day) under normal conditions (Dempster et al. 2008, 2009). This jumping behaviour is linked to the physostomous swim bladder that salmon possess, which is filled and emptied via the oesophagus (Fänge 1953). Air must be swallowed at the surface to fill the swim bladder, and denial of access to the surface (submergence) results in the gradual deflation of the swim bladder over time, causing negative buoyancy in the fish (Dempster et al. 2009, Korsøen et al. 2009). Consequently, the frequency and intensity of jumping when surface access is reinstated is increased (Dempster et al. 2011).

This surface behaviour, enhanced by submergence, can be coupled with a chemical therapeutant infused in oil and floated in a thin layer over the surface waters of the sea-cage (Boxaspen \& Holm 2001). The fish will delouse themselves by breaking the chemical layer at the surface. It is probable that the fish will be unaffected by the chemical as salmon skin is lipophobic, whereas the therapeutant will permeate the external, lipophilic cuticle of sea lice (Kabata 1974). This method will likely permit the re-collection of the chemical with skimmers attached to the edges of the cage, eliminating negative environmental impacts (Dempster et al. 2011). The limitation to this method is that efficient application may not be achieved at certain times of the year when UV levels are high (Furevik et al. 1993), as the active compound in the chemical, pyrethrum, degrades in a few hours in sunlight (Boxaspen \& Holm 2001). In addition, if fish do not break the surface frequently enough, they will not be treated before the pyrethrum degrades.

To ensure the effectiveness of this treatment, each individual must be exposed to the therapeutant. In one summer trial, Dempster et al. (2011) showed that submergence for 24 to $48 \mathrm{~h}$ resulted in $93 \%$ of fish jumping within $2 \mathrm{~h}$ of restoring surface access, with each fish jumping 2.5 to 3 times. However, effects of this treatment may vary with fish size, season or location. To improve the method further, we hypothesise that the application of certain cues during submergence may enhance the frequency and intensity of swim-bladder refilling behaviours after submergence, particularly if they can reduce the amount of air in the swim bladder. This could be achieved by briefly exposing the fish to aversive physical cues, which may induce an accelerated deflation of the swim bladder; emergency reactions of the sympathetic nervous system produce a deflatory reflex, to regulate buoyancy and facilitate escape into deeper waters (Fänge 1953). Salmon exposed to acute changes in the light environment exhibit a flight response by diving away from the light source and increasing swimming activity (Mork \& Gulbrandsen 1994, Bratland et al. 2010, Folkedal et al. 2010, S. Bui et al. unpubl. data). The application of low-level light for brief periods results in negligible short-term welfare effects, and the fish return to pre-stimulus behaviour within 20 min (S. Bui et al. unpubl. data).

Alternatively, the use of a feeding event may affect the volume of the swim bladder by reducing the space available in the stomach cavity (Ona 1990). There have been no studies conducted on how feed influences the buoyancy of fish in the wild or in production systems, and this knowledge would assist in understanding swimming behaviours of fish in relation to buoyancy instead of hunger motivation. Under normal aquaculture conditions, there is an increase in bubbles released from the swim bladder during feeding, indicating that the fish are releasing air to compensate for the ascent to shallow waters. Analogous observations have been made in vertically migrating coregonids (Knudsen \& Gjelland 2004), which also have a physostomous swim bladder. Furthermore, responses to the provision of feed during or after a 
stressful event can provide information concerning the welfare status of salmon (Folkedal et al. 2012a), and will enable a proxy assessment of their well-being (Dawkins 2003, Folkedal et al. 2012b).

Here, we aimed to test if the application of light stimuli or feeding during submergence changed the frequency and intensity of jumping behaviour after a period of submergence. We investigated these hypotheses by removing access to the surface and applying a light stimulus, feed event, a light stimuli and feed event combined, or no stimuli (control). By observing the jumping behaviour once surface access was reinstated, we could infer measures that would enhance the efficiency of a floating chemical therapeutant, namely the proportion of fish that jumped, the frequency of jumps each fish exhibited, and the time taken until each fish first jumped.

\section{MATERIALS AND METHODS}

\section{Location and experimental setup}

The experiment was conducted at the research station of the Institute of Marine Research in Masfjorden, western Norway $\left(60^{\circ} \mathrm{N}\right)$, from February 6 to March 24, 2012 (hereinafter referred to as the experimental period). We used a prototype net cage $\left(5.5 \times 5.5 \times 9 \mathrm{~m}_{i} \approx 272 \mathrm{~m}^{3} ;\right.$ Egersund Group), which was a standard net cage with a surface access chamber sewn into it (Fig. 1). The surface access chamber was connected by a roof of netting material attached $1 \mathrm{~m}$ below the top of the cage, and consisted of a $3 \times 3 \times 3 \mathrm{~m}$ aluminium frame with clear plastic walls and a removable netted roof. The base of the surface access chamber was open, allowing fish to swim up and access the surface within the chamber. When submerged, the top of the surface access chamber was suspended at 1 to $1.5 \mathrm{~m}$ depth. In the raised position, the top $1.5 \mathrm{~m}$ was above the water and the netted roof was removed to assist surface observations.

\section{Experimental design}

We used light stimuli or a feed event to test how these cues would affect the occurrence and frequency of surface activities after a period of submergence. The design included a control (surface access denied through the submergence of the cage), light (fish exposed to a $10 \mathrm{~min}$ period of light during submergence), a feed event (fish fed for 10 min during submergence), and a combination of light and feed (both treatments applied in the same manner as for individual treatments). Each treatment was conducted once within a week, and each treatment was replicated 5 times in different orders within weeks to avoid possible confounding due to environmental variability.

For all replicates, the surface access chamber was submerged between 15:00 and 16:00 h; light periods began 5.5 to $7 \mathrm{~h}$ later (when there was complete ambient darkness), feed periods began 17 to $18 \mathrm{~h}$ after submergence, and the cage was raised after a total submergence time of 18 to $19.5 \mathrm{~h}$. For the $2 \mathrm{~h}$ immediately following the reinstatement of surface access, jumping behaviours were recorded. We measured the proportion of fish in the group that jumped, the number of jumps exhibited by each individual, and the time elapsed until the first jump was seen in an individual.

\section{Light and feed treatments}

An LED lamp (AKVA Group) was suspended in the centre of the surface access chamber $0.5 \mathrm{~m}$ below the 
bottom of the frame, and remained in the cage throughout the experimental period. The lamp emitted a blue light (peak at $460 \mathrm{~nm}$; colour temperature of $20000 \mathrm{~K}$ ) with a power rating of $400 \mathrm{~W}$. Turning on this light at low intensity (photosynthetic photon flux fluence rate $=0.82 \mu \mathrm{mol} \mathrm{m} \mathrm{m}^{-2} \mathrm{~s}^{-1}$ at a point $0.5 \mathrm{~m}$ next to the lamp) for $10 \mathrm{~min}$ at night elicits an avoidance diving response in the fish, without adverse behavioural effects, and leads to a $29 \%$ reduction in echosignal which correlates with swim bladder size (S. Bui et al. unpubl. data).

Schools of salmon provided with abundant feed can become satiated in approximately $13 \mathrm{~min}$ (Talbot et al. 1999). Hence, for feed treatments, $200 \mathrm{~g}$ of pellets (4.5 $\mathrm{mm}$ Skretting Spirit) was thrown into the cage by hand over $10 \mathrm{~min}$, with the feed sinking down through the roof netting into the surface access chamber space.

\section{Experimental fish}

Each replicate used 10 Atlantic salmon Salmo salar, with a total of 200 fish used in this experiment (10 fish $\times 4$ treatments $\times 5$ replicates). The fish weighed on average $333.4 \pm 8.1 \mathrm{~g}$ (mean $\pm \mathrm{SE}$; range: 125 to $860 \mathrm{~g}$ ) and had a total length of $32.7 \pm 0.2 \mathrm{~cm}$ (range: 24 to $43 \mathrm{~cm}$ ). There was no difference in mean weight $\left(1\right.$-way ANOVAs; $\left.F_{3,195}=1.826, \mathrm{p}=0.14\right)$ or length (1-way ANOVAs; $\left.F_{3,195}=2.08, \mathrm{p}=0.10\right)$ among treatments.

A $5 \times 5 \times 5 \mathrm{~m}$ stock cage held all of the experimental fish, which was visually separated from the experimental cage to avoid light contamination from the light treatment. Fish were not fed for $24 \mathrm{~h}$ prior to being put into the experimental cage. Before each trial, 10 individuals were collected with a hand net and anaesthetised with Finquel (tricaine methanesulfonate, Western Chemical; dose $100 \mathrm{mg} \mathrm{l}^{-1}$ of seawater), then tagged with a unique colour-coded external T-bar tag $(11 \mathrm{~cm}$, Hallprint) inserted adjacent to the dorsal fin (Dempster et al. 2011). Fish were then put into the experimental cage, where they were allowed to recover for $1 \mathrm{~h}$ before submergence. No mortalities were recorded in any replicate.

\section{Surface jumping behaviours}

Surface activity was monitored by 3 cameras (VNSVUC-Z10, Scan Secure, www.secure.no) mounted onto the top frame of the surface access chamber facing downwards, and 1 mounted to the bottom frame facing upwards (Fig. 1, 3rd camera on top frame not shown). The cameras gave $100 \%$ coverage within the surface access chamber at multiple angles, so that fish could be identified with confidence from their unique tags during any surface activities. Videos were recorded and reviewed using Geovision (Scan Secure) software, while fish were also observed directly by an observer during the surface period. For each jump, the tag colour of the fish and the time elapsed since the surface access chamber was raised was recorded.

\section{Environmental variables}

Temperature and salinity were recorded daily throughout the experimental period using an online probe (YSI model 30-50 ft). Measurements were taken at depths from 0 to $10 \mathrm{~m}$, at a standard time and reference point near the experimental cage. Visibility in the water was consistently $>20 \mathrm{~m}$ over the experimental period, as confirmed by an upwardfacing underwater camera suspended underneath the farm at $30 \mathrm{~m}$ depth.

\section{Statistical analyses}

Differences in temperature and salinity among treatments were tested for with 1-way ANOVA. Test assumptions (normality and homogeneity of variances) were evaluated by assessing residual plots. Temperature was averaged across depth bands (0-2, 3-5 and 6-8 m) for analysis. For measures of the proportion of fish that jumped, number of jumps per fish, and time until first jump, the differences in means of treatment groups were tested with 2-way ANOVA. Factors were the occurrence of Light or Feed in the treatment. Statistical significance was determined at $\alpha=0.05$.

\section{RESULTS}

The salmon exhibited distinct jumping behaviours when access to the surface was reinstated. When an individual ascended to the surface, there was a pronounced action to take in air - a behaviour that often occurred simultaneously with other fish-followed by rapid descent to below the surface access chamber. The behaviour of the group was variable towards the surface access chamber, even within treatments, suggesting that other extrinsic factors may have 
affected their behaviour. Some groups in various treatments avoided swimming within the surface access chamber completely, whereas other groups swam in the small space for the first 30 min after the surface access chamber was raised.

The application of light or feed during submergence had similar effects on submerged individuals and their jumping behaviours when surface access was granted. Analyses showed a significant interaction between light and feed $\left(F_{1,16}=11.76, \mathrm{p}=0.003\right)$, with an average of 82 and $84 \%$ of fish jumping in groups exposed to light and feed, respectively, and $70 \%$ jumping when both stimuli were applied together (Fig. 2a). These were higher than the percentage exhibited in control groups (50\%; Fig. 2a) All 3 treatments increased the number of jumps exhibited by individuals $\left(F_{1,16}=7.41, \mathrm{p}=0.015\right)$, with salmon exposed to light jumping on average 1.7 times and 1.5 times if fed, while the average for combination groups was 0.98 times (Fig. 2b). There was no difference between the treatment groups, but all were higher than controls (0.92 jumps on average; Fig. 2b). The time elapsed until the first jump by each individual did not differ among treatments, for the main effects or the interaction term $\left(F_{1,16}<2.15, \mathrm{p}>\right.$ 0.16 ), with average times ranging from 31 to $50 \mathrm{~min}$ (Fig. 2c).

The experiment was not confounded by environmental variables, as there was no difference in temperature $\left(F_{3,15}>0.27, \mathrm{p}>0.6\right)$ or salinity $\left(F_{3,15}>\right.$ $0.15, \mathrm{p}>0.6$ ) among treatments. Although there was no evidence of a strong halocline, a thermocline was present where the colder surface temperatures extended deeper in the latter 3 experimental blocks to depths including waters within and just below the surface access chamber, at roughly $4 \mathrm{~m}$ depth (Fig. 3). Generally, the warmest waters were always at the bottom of the cage at $9 \mathrm{~m}$, which may have motivated the swimming depth of the fish.

\section{DISCUSSION}

\section{Responses of fish to light and feed during submergence}

The use of light and feed increased surface-oriented behaviours when implemented during submergence, whereby the proportion of fish jumping and the number of times an individual jumped was higher in groups exposed to light or feed. In comparison to the present study in winter, where jumping activity was 1 to 1.7 times per fish after submergence for 18 to
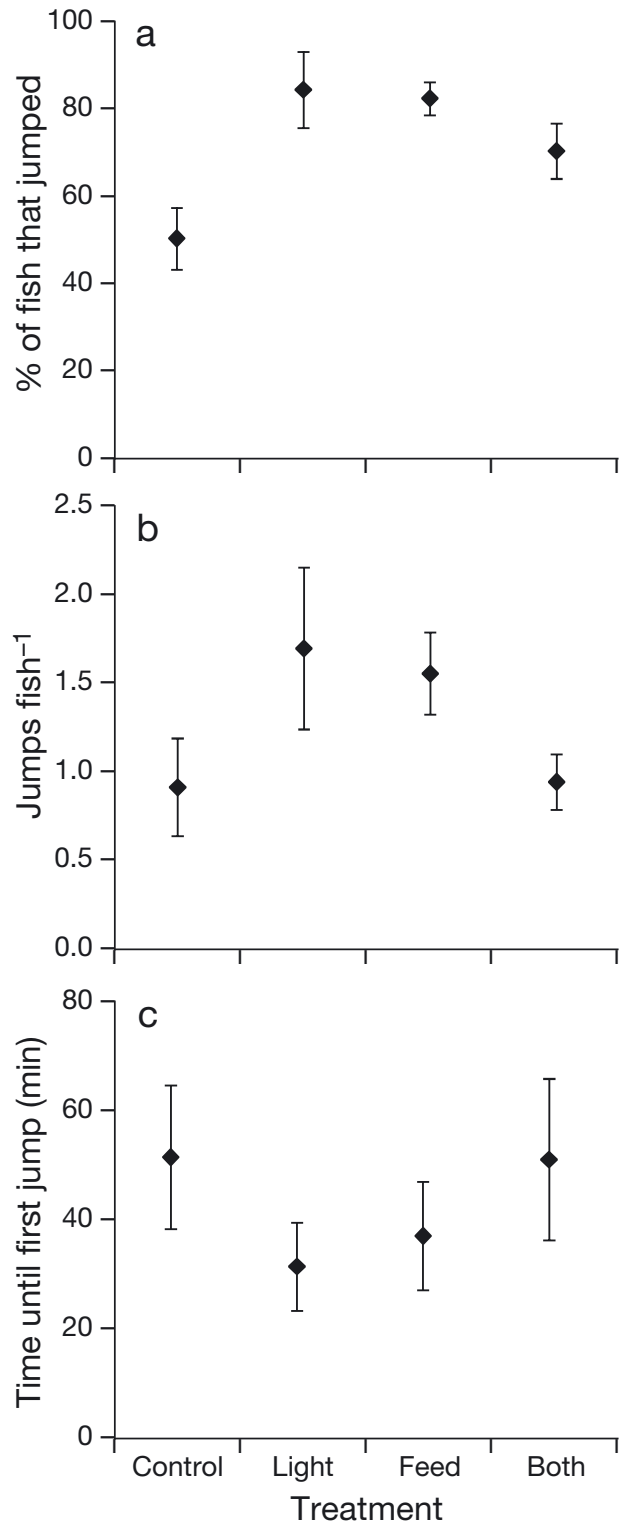

Fig. 2. Salmo salar. Surface-oriented behaviours of farmed Atlantic salmon for each treatment within a $2 \mathrm{~h}$ period after surface access was reinstated. (a) Percentage of individuals that jumped at the surface; (b) average number of jumps exhibited per fish; (c) time elapsed since surface access was granted until the first jump by each fish. All values shown are mean \pm SE for 5 replicates

$19.5 \mathrm{~h}, 93 \%$ of salmon jumped 2.5 to 3 times after submergence for 24 to $48 \mathrm{~h}$ in a study by Dempster et al. (2011) in summer. The motivation to jump is known to vary with submergence time (Dempster et al. 2011), but may also vary among seasons, level of sea lice infestation, or size and age of the fish. The present study was conducted during a colder time of the year and used younger, smaller fish, which are factors that could change the motivations and hence 


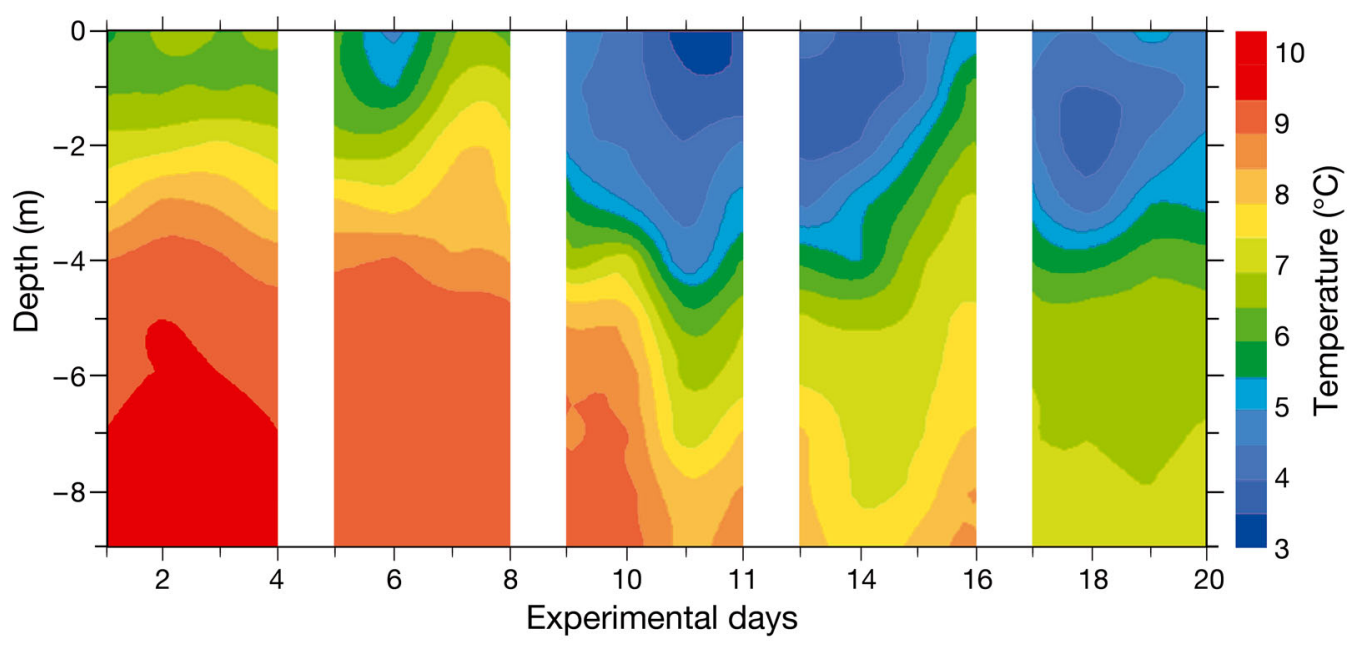

Fig. 3. Temperature profile from depths of 0 to $9 \mathrm{~m}$ at the experimental site. Data was taken from an online probe for every experimental day

behaviours of individuals. In this experiment, the warmest waters were deep in the cage, which likely motivated the fish to swim deeper due to thermal preference (Oppedal et al. 2011a), held them away from the surface and decreased the motivation to jump. Furthermore, fish infected with sea lice have been reported to increase jumping behaviours in an effort to dislodge the lice (Furevik et al. 1993), but in the present study there were no sea lice present on the experimental fish. The provision of a light stimulus during submergence increased jumping frequency by 1.7 times compared to submergence only, and hence light could be used at times of the year when the fish are less likely to jump (i.e. colder months) to enhance the behaviour further and increase the effect of submergence. Feed events may also provide positive welfare outcomes, as there were no dramatic changes in the daily routine or physical manipulation of the fish. These could be used at any time throughout the year.

Intrinsic factors may influence the surface behaviour of salmon, such as swim-bladder size, stimuli sensitivity, body condition, spatial preference and feeding motivation. Farmed salmon exhibit a tradeoff in spatial preferences within the cage, dependent on temperature, oxygen, salinity (Oppedal et al. 2011a) and stocking density (Oppedal et al. 2011b), and the motivation to come to the surface may vary if the strength of other preferences are greater than the desire to re-fill the swim bladder. The temperatures during the last 3 replicates were colder at the surface compared to the first 2 replicates, which may have deterred the salmon from swimming in the shallower waters and consequently in the surface access chamber.
The use of light to influence fish behaviour has become common in aquaculture and behavioural research; however, unlike previous research, the present study links the effect of exposure to light with surface activity. Atlantic salmon are sensitive to blue-green light wavelengths (Ali 1961), and as this spectrum of light has the highest penetration energy through seawater, sudden exposure to light during periods of darkness will be aversive for the fish. This experience induces dramatic changes in activity and vertical distribution of salmon (Eaton \& Hackett 1984, Mork \& Gulbrandsen 1994, Folkedal et al. 2010) and immediate flight away to darker areas (Bratland et al. 2010). The increase in swim bladder re-filling behaviour after exposure to light supports the hypothesis that salmon release gas from the swim bladder in order to facilitate the escape response (Fänge 1953). This is further supported by evidence from echosounder data of a decline in swim-bladder volume following short-term exposure to aversive light (S. Bui et al. unpubl. data). While acute exposure to light elicits a strong response, further research must address the issue that with increasing use of light stimuli, salmon may become habituated to the cue and no longer consider it threatening (Stien et al. 2007, Bratland et al. 2010, Folkedal et al. 2010).

The effectiveness of a feed event to induce surface behaviours may differ throughout the year as factors that influence feed motivation vary. For example, appetite is greatest when water temperature is warm and leads to fish moving towards the surface in warmer months prior to feed events (Juell et al. 2003, Juell \& Fosseidengen 2004). Appetite and feed intake changes with body size and during changing lifehistory stages (Austreng et al. 1987, Huntingford et 
al. 2012). Hence, during the winter, when the present experiment was conducted, the feed effect should be weakest, as appetite and feed intake is lowest. The use of feed to influence surface activity might therefore elicit a greater response during the warmer months. Further, feeding motivation and surface attraction may be increased by hunger (e.g. Juell et al. 1994, Oppedal et al. 2011a), and starvation for a short period may increase the feeding response and thereby the following air loss and surface response. In the present study, the fish were not fed for $24 \mathrm{~h}$ before the trial, which is not long enough to drive a greater feeding response. Further, appetite would likely have been low due to the anaesthetic and tagging involved in the trial. Therefore, the effect we observed for the feed treatment may be greater when the fish are under normal conditions.

This work provides the first correlational evidence that a feed event reduces buoyancy in fish, prompting thought about the mechanisms underlying this relationship. The most likely explanation is that the consumption of pellets fills the stomach, reducing the space available in the body cavity for the swim bladder. As such, the swim bladder deforms and loss of air occurs. In Atlantic cod, a full stomach results in the swim bladder being reduced to $10 \%$ of its original volume (Ona 1990). An alternate explanation for air loss due to feed events is that fish are more vertically mobile in the water column during feeding (Oppedal et al. 2011a) and may lose air due to the decrease in partial pressure or the rapid movements themselves. Air in the swim bladder may hinder the fast vertical movements required during feeding, and if this were the case, salmon would release gas from the swim bladder at the beginning of or during a feeding event. If the mechanism for air loss is related to decreased swim-bladder space due to the stomach filling, or the release of air during the onset of feeding, then it is unlikely that its effect will lessen over time in terms of reducing buoyancy and increasing surface behaviours.

\section{Surface-based delousing using submergence and light or feed}

We did not measure or compare stress levels among treatments in this experiment, nor has stress been measured and compared to controls in previous submergence trials, although short-term submergence for up to $3 \mathrm{wk}$ does not affect salmon growth or condition (Dempster et al. 2009). Any possible negative impacts of short-term submergence should be compared to those induced by current methods of sea lice control, for which accurate data are currently lacking. During chemical bathing, fish experience crowding, oxygen depletion, degrading water conditions, a shift away from their preferred swimming depths, and physical irritation from the toxic delousing therapeutant during the chemical bath. With submergence, alone or combined with additional light stimuli or feeding, fish are less likely to experience these negative welfare parameters. The fish do not exhibit a panic reaction during the process of submerging the cage (Korsøen et al. 2012b), and with increasing contact with the surface access chamber, they could become accustomed to using it. Further, the jumping behaviour salmon exhibit after submergence is within their natural behavioural repertoire, and enhancement of this behaviour is unlikely to affect their welfare status. Scramble competition for space and thus crowding of fish at the surface may be an issue when the technique is applied at commercial scales; further development of this method must ensure the space within the surface access chamber is adequate.

The combination of surface behaviour and a floating therapeutant (Boxaspen \& Holm 2001) may allow for the collection of chemical material following treatment to prevent environmental pollution. With further testing, it may deliver a more effective delousing method due to the specificity of the chemical and the lack of avoidance of the medicine (Dempster et al. 2011), decreasing the possibility for sea lice to develop resistance to the chemical (Murray 2011).

\section{CONCLUSIONS}

This study develops our knowledge in identifying and focusing the natural behaviours of farmed aquatic animals, and how behaviour may be incorporated into a production application to improve their welfare. Submerging the sea-cage in combination with feed or light stimuli encourages salmon to break the surface, effectively crowding the fish without the need for physical manipulation. This approach could be used to assist in the innovation of methods to treat sea lice, while minimising the negative impacts that sea lice have on both salmon production and surrounding ecosystems. Further testing of the method is required to determine if the methods are applicable at full scale. While we focus on one particular application here, this knowledge could be used to develop other methods for procedures conducted in production systems. 
Acknowledgements. We thank Jan Olav Fosse, Kristian Dale, Tone Vågseth, Jan-Erik Fosseidengen, and Kåre Storsæter for their technical support. Funding was provided by the Norwegian Research Council through the Centre for Research-Based Innovation in Aquaculture Technology (CREATE). The work was conducted in accordance with the laws and regulations of the Norwegian Regulation on Animal Experimentation 1996.

\section{LITERATURE CITED}

Ali MA (1961) Histophysiological studies on the juvenile Atlantic salmon (Salmo salar) retina. Can J Zool 39: 511-525

- Austreng E, Storebakken T, Åsgård T (1987) Growth rate estimates for cultured Atlantic salmon and rainbow trout. Aquaculture 60:157-160

Bergh $\varnothing$ (2007) The dual myths of the healthy wild fish and the unhealthy farmed fish. Dis Aquat Org 75:159-164

> Boxaspen K, Holm JC (2001) The development of pyrethrumbased treatments against the ectoparasitic salmon lice Lepeophtheirus salmonis in sea cage rearing of Atlantic salmon Salmo salar L. Aquacult Res 32:701-707

> Bratland S, Stien LH, Braithwaite VA, Juell JE and others (2010) From fright to anticipation: using aversive light stimuli to investigate reward conditioning in large groups of Atlantic salmon (Salmo salar). Aquacult Int 18:991-1001

Burridge L, Weis JS, Cabello F, Pizarro J, Bostick K (2010) Chemical use in salmon aquaculture: a review of current practices and possible environmental effects. Aquaculture 306:7-23

> Costello MJ (2006) Ecology of sea lice parasitic on farmed and wild fish. Trends Parasitol 22:475-483

> Costello MJ (2009) How sea lice from salmon farms may cause wild salmonid declines in Europe and North American and be a threat to fishes elsewhere. Proc R Soc Lond B Biol Ser 276:3385-3394

Dawkins MS (2003) Behaviour as a tool for assessment of animal welfare. Zoology 106:383-387

> Dempster T, Juell JE, Fosseidengen JE, Fredheim A, Lader P (2008) Behaviour and growth of Atlantic salmon (Salmo salar L.) subjected to short-term submergence in commercial scale sea-cages. Aquaculture 276:103-111

> Dempster T, Korsøen ØJ, Folkedal O, Juell JE, Oppedal F (2009) Submergence of Atlantic salmon (Salmo salar L.) in commercial scale sea-cages: a potential short-term solution to poor surface conditions. Aquaculture 288: 254-263

> Dempster T, Kristiansen TS, Korsøen ØJ, Fosseidengen JE, Oppedal F (2011) Technical note: modifying Atlantic salmon (Salmo salar) jumping behavior to facilitate innovation of parasitic sea lice control techniques. J Anim Sci 89:4281-4285

> Denholm I, Devine GJ, Horsberg TE, Sevatdal S, Fallang A, Nolan DV, Powell R (2002) Analysis and management of resistance to chemotherapeutants in salmon lice, Lepeophtheirus salmonis (Copepoda: Caligidae). Pest Manag Sci 58:528-536

Eaton RC, Hackett JT (1984) The role of Mauthner cells in fast-starts involving escape in teleost fish. In: Eaton RC (ed) Neural mechanisms of startle behavior. Plenum Press, New York, NY, p 213-266

Fänge $R$ (1953) The mechanism of gas transport in the euphysoclist swimbladder. Acta Physiol Scand 23(Suppl
110):1-133

Folkedal O, Torgersen T, Nilsson J, Oppedal F (2010) Habituation rate and capacity of Atlantic salmon (Salmo salar) parr to sudden transitions from darkness to light. Aquaculture 307:170-172

Folkedal O, Torgersen T, Olsen RE, Fernö A and others (2012a) Duration of effects of acute environmental changes on food anticipatory behaviour, feed intake, oxygen consumption, and cortisol release in Atlantic salmon parr. Physiol Behav 105:283-291

Folkedal O, Stien LH, Torgersen T, Oppedal F and others (2012b) Food anticipatory behaviour as an indicator of stress response and recovery in Atlantic salmon postsmolt after exposure to acute temperature fluctuation. Physiol Behav 105:350-356

Furevik DM, Bjordal Å, Huse I, Fernö A (1993) Surface activity of Atlantic salmon (Salmo salar L.) in net pens. Aquaculture 110:119-128

Heuch PA, Mo TA (2001) A model of salmon louse production in Norway: effects of increasing salmon production and public management procedures. Dis Aquat Org 45: $145-152$

> Jimenez DF, Heuch PA, Revie CW, Gettinby G (2012) Confidence in assessing the effectiveness of bath treatments for the control of sea lice on Norwegian salmon farms. Aquaculture 344-349:58-65

> Jones MW, Sommerville C, Wootten R (1992) Reduced sensitivity of the salmon louse, Lepeophtheirus salmonis, to the organophosphate dichlorvos. J Fish Dis 15:197-202

> Juell JE, Fosseidengen JE (2004) Use of artificial light to control swimming depth and fish density of Atlantic salmon (Salmo salar) in production cages. Aquaculture 233:269-282

Juell JE, Fernö A, Furevik D, Huse I (1994) Influence of hunger level and food availability on the spatial distribution of Atlantic salmon, Salmo salar L., in sea cages. Aquacult Fish Manag 25:439-451

> Juell JE, Oppedal F, Boxaspen K, Taranger GL (2003) Submerged light increases swimming depth and reduces fish density of Atlantic salmon Salmo salar L. in production cages. Aquacult Res 34:469-477

Kabata Z (1974) Mouth and mode of feeding of Caligidae (Copepoda) parasites of fishes, as determined by light and scanning EM. J Fish Res Board Can 31:1583-1588

> Knudsen FR, Gjelland KØ (2004) Hydroacoustic observations indicating swimbladder volume compensation during diel vertical migration in coregonids (Coregonus lavaretus and Coregonus albula). Fish Res 66:337-341

Korsøen ØJ, Dempster T, Fjelldal PG, Oppedal F, Kristiansen TS (2009) Long-term culture of Atlantic salmon (Salmo salar L.) in submerged cages during winter affects behaviour, growth and condition. Aquaculture 296: 373-381

Korsøen ØJ, Dempster T, Oppedal F, Kristiansen T (2012) Individual variation in swimming depth and growth in Atlantic salmon (Salmo salar L.) subjected to submergence in sea-cages. Aquaculture 334-337:142-151

Krkoŝek M, Lewis MA, Volpe JP (2005) Transmission dynamics of parasitic sea lice from farm to wild salmon. Proc R Soc Lond B Biol Sci 272:689-696

Krkoŝek M, Revie CW, Gargan PG, Skilbrei OT, Finstad B, Todd CD (2013) Impact of parasites on salmon recruitment in the Northeast Atlantic Ocean. Proc R Soc Lond B Biol Sci 280:20122359, doi:10.1098/rspb.2012.2359

Mork OI, Gulbrandsen J (1994) Vertical activity of four 
salmonid species in response to changes between darkness and two intensities of light. Aquaculture 127: 317-328

Murray AG (2011) A simple model to assess selection for treatment-resistant sea lice. Ecol Model 222:1854-1862

Ona E (1990) Physiological factors causing natural variations in acoustic target strength of fish. J Mar Biol Assoc UK 70:107-127

Oppedal F, Dempster T, Stein LH (2011a) Environmental drivers of Atlantic salmon behaviour in sea-cages: a review. Aquaculture 311:1-18

Oppedal F, Vågseth T, Dempster T, Juell JE, Johansson D (2011b) Fluctuating sea-cage environments modify the effects of stocking densities on production and welfare

Editorial responsibility: Ian Fleming,

St. John's, Newfoundland and Labrador, Canada parameters of Atlantic salmon (Salmo salar L.). Aquaculture 315:361-368

Stien LH, Bratland S, Austevoll I, Oppedal F, Kristiansen TS (2007) A video analysis procedure for assessing vertical fish distribution in aquaculture tanks. Aquacult Eng 37: $115-124$

Talbot C, Corneillie S, Korsøen ØJ (1999) Pattern of feed intake in four species of fish under commercial farming conditions: implications for feeding management. Aquacult Res 30:509-518

Westcott JD, Hammell KL, Burka JF (2004) Sea lice treatments, management practices and sea lice sampling methods on Atlantic salmon farms in the Bay of Fundy, New Brunswick, Canada. Aquacult Res 35:784-792

Submitted: September 26, 2012; Accepted: December 10, 2012 Proofs received from author(s): January 28, 2013 